\title{
Production and optimization of Polyhydroxybutyrate and its application in bioplastic production
}

\author{
S.A. Kate ${ }^{1 *}$, D.R. Hire ${ }^{2}$, N.M. Pawar ${ }^{3}$ \\ ${ }^{1,2,3}$ Department of Biotechnology, Shivchhatrapati College, BAMU, Aurangabad, India \\ *Corresponding Author:savitaakate@gmail.com, Tel: 9011553369
}

Available online at: www.isroset.org

Received: 29/Mar/2019, Accepted: 15/Apr/2019, Online: 30/Apr/2019

\begin{abstract}
Polyhydroxybutyrate (PHB) is a natural biopolymer by wide range of microbes which is a storage granule used by microbes as an energy as well as carbon source. PHB exhibit stiffness, brittle to rubber like, biodegradable, environment friendly properties. In present work isolates was produced Polyhydroxybutyrate by using Nitrogen deficient medium and modified LB medium with glucose as carbon source. Maximum production was observed in Modified LB medium as compared to nitrogen deficient medium. Extraction of bacterial PHB was done by sodium hypochlorite method; selected bacteria produced $2.10 \mathrm{~g} / \mathrm{L}$ PHB .Confirmation of PHB molecule was by FTIR \& TLC. Extracted bacterial PHB was capable to produce biodegradable plastic which shows water tolerance activity. PHB production was found to be maximum at optimum $\mathrm{pH} 7.5,37^{\circ} \mathrm{C}, 3 \%$ inoculums percentage and glucose concentration $20 \mathrm{~g} / \mathrm{L}$.
\end{abstract}

Keywords- PHB, Nitrogen deficient medium, Modified LB medium, FTIR, TLC, Biodegradable plastic

\section{INTRODUCTION}

Polyhydroxybutyrate(PHB) is member of polyhydroxyalkanoates (PHAs) family that is found in varieties of microorganisms as reserve food material. PHB are accumulated by different microorganisms such as bacteria, fungi, Achaea, yeast under aerobic condition when carbon source is in excess amount but one or several nutrients such as nitrogen, sulfur, phosphorus are limited ${ }^{[1]}$. There are more than 300 species which produce PHB. Shape, size, structure, physical properties of these granules are differing from organism to organism ${ }^{[2]}$. PHB degrade naturally and completely to carbon dioxide and water under natural environment by different microorganisms ${ }^{[3]}$.

French microbiologist Maurice Lemoigne in 1923 first time isolated and characterized PHB ${ }^{[4]}$.PHB has various applications such as in agriculture, bioimplants, bioplastic production, biofuel production, drugs and chemicals, food and feeds, etc. There are many applications of bioplastic as they were used for the fabrication of bottles, fibers, latex and several products of agriculture, commercial or packaging interest $^{[5]}$.

The exponential growth of human population has led to the accumulation of huge amounts of non-degradable plastics across our planet ${ }^{[6]}$. Plastics are extremely diverse in terms of chemical composition, properties and possible applications, widely distributed in the society and the environment. The petroleum based plastics are indispensible to our daily life. The usage of plastics cannot be eradicated right away, but management of plastic waste product should be done to avoid detrimental effects to humans. The best way for decomposing plastics is microbial degradation or biodegradation. Microbial degradation of plastics is caused by enzymatic activities that lead to a chain cleavage of the polymer into monomer. Microorganisms utilize polythene film as a soul source of carbon resulting in partial degradation of plastics. Many solid waste management programs have been conducted by various countries to reduce plastic waste and have come up with new ways to produce biodegradable plastic materials such as Polyhydroxybutyrates (PHBs) also called as bioplastic ${ }^{[2]}$.

PHB is water insoluble and relatively resistant to hydrolytic degradation. PHB shows good oxygen permeability. PHB has good UV- resistant but has poor resistance to acids and bases. PHB is soluble in chloroform and other chlorinated hydrocarbons ${ }^{[6]}$. PHB is nontoxic, less sticky when melted which making it a potentially good material for clothing in the future. There are many advantages of Bioplastics over petroleum-based polymers like PHB is natural polymer, its degradation takes 5-6 weeks in microbe active environments. The synthesis and biodegradation of biopolymers are totally compatible to the carbon cycle. The wider use of bioplastics in daily life will solve the increasing problem of organic waste ${ }^{[5]}$. 
The present study focus on the Production and optimization of Polyhydroxybutyrate and its application in eco-friendly bioplastic production.

\section{RELATED WORK}

Commercial production of PHB by Bacillus and its utilization as cheaper substance. Synthetic plastics are used due to their durability, strengths, shape, and moldable property but they are non-degradable, difficult to dispose. To overcome this problem, the production of eco-friendly bioplastic becomes unavoidable. Polyhydroxybutyrate is a biopolymer produced by microorganisms ${ }^{[5]}$.

\section{MATERIALS AND METHOD:}

\section{Materials:}

Nutrient broth, Potato Dextrose Agar, Sudan Black B Stain, Sodium Hypochlorite, Chloroform (Hi media). All chemicals are of analytical grade.

\section{Collection of Sample:}

Soil samples and waste water sample were collected from sugarcane farm and cardboard industry respectively in sterile container and labeled them ${ }^{[1]}$ for the isolation of PHB producer.

\section{Isolation, Screening and Identification of PHB producing bacteria:}

PHB producing bacteria were isolated on nutrient agar by serial dilution method from sugarcane farm soil and cardboard industry waste water ${ }^{[7]}$. Bacterial isolates with different size ,shape, color and morphology were further proceed for PHB screening on nutrient agar by Sudan Black B staining where PHB producers appear bluish black color while non PHB producers remain white ${ }^{[1]}$.Most proficient PHB bacterial isolates were promote for identification as per Bergey's manual of systemic bacteriology ${ }^{[6]}$.

\section{Production and Extraction of PHB:}

Triplicates sets of $250 \mathrm{ml}$ flask containing $200 \mathrm{ml}$ modified LB medium and Nitrogen deficient medium was inoculated by PHB producing bacteria, incubated at $37^{\circ} \mathrm{C}$ for $3-5$, days ${ }^{[8]}$.After incubation, culture medium proceed for extraction. Fermentation medium was centrifuged at $10,000 \mathrm{r} / \mathrm{min}$ for 15 min., sodium hypochlorite $(10 \mathrm{ml})$ was added to collected pellet and incubated at $50^{\circ} \mathrm{C}$ for 1 hour. Cell lysis obtained was centrifuged at $10,000 \mathrm{r} / \mathrm{min}$ for $30 \mathrm{~min}$, obtained pellet was one by one washed with $\mathrm{D} / \mathrm{W}$, ethanol and acetone. After washing, pellet was dissolved in $10 \mathrm{ml}$ of chloroform then incubated overnight at $40^{\circ} \mathrm{C}$. PHB obtained in the form of dried powder ${ }^{[7]}$. Extracted bacterial PHB was capable to produce bioplastic sheet.

\section{Optimization parameters for PHB production:}

Effect of different parameters like temperature, $\mathrm{pH}$, inoculums percentage \& glucose concentration was studied to optimize PHB production ${ }^{[3]}$.All experiments were runs in triplicates.

\section{Effect of inoculums percentage:}

Triplicate set of modified LB medium were inoculated by $1 \%$ to $5 \%$ of inoculums, incubated at $37^{\circ} \mathrm{C}$ for $2-3$ days at stationary after incubation the aliquots of the medium was subjected for PHB extraction. PHB were quantified by weights.

\section{Effect of Glucose concentration, temperature and $\mathrm{pH}$ on PHB production:}

The isolates were grown in modified LB medium with different concentration of glucose $(5 \mathrm{~g} / \mathrm{L}$ to $20 \mathrm{~g} / \mathrm{L})$, temperature ranges from $10^{\circ} \mathrm{C}, 30^{\circ} \mathrm{C}, 37^{\circ} \mathrm{C} \& 45^{\circ} \mathrm{C}$ and the medium was prepared with different $\mathrm{pH}$ ranging from (6.08.5) \& inoculated flasks were incubated at $37^{\circ} \mathrm{C}$ for 2-3 days at stationary state. After incubation PHB was evaluated by calculating dry weight of PHB.

\section{Characterization of PHB:}

PHB characterization was done by FTIR (Chemical technology, Dr. BAMU, Aurangabad) and Thin Layer Chromatography. In TLC, 20 $\mu 1$ of extracted PHB sample was spotted on TLC plate \& allowed to run three fourth in solvent system (ethyl acetate \& benzene (1:1)) mixture. Then the TLC plate was placed in iodine chamber for vaporization to made spot visible ${ }^{[8]}$.

\section{Preparation of bioplastic sheet:}

For Bioplastic sheet preparation, obtained PHB powder was melted in the hot chloroform and caste on sterile petriplate to form thin sheet.This was allowed to dry and stabilized for 48 $\mathrm{hrs}^{[9]}$, and check its water tolerance property.

\section{RESULTS}

Isolation, Screening and Identification of PHB producing microbes:

34 bacteria were isolated from soil \& cardboard industry waste water sample by serial dilution \& spread plate technique, out of 34 bacteria 25 bacteria shown PHB accumulation which was screened by Sudan Black B staining method, PHB producers appear bluish black color while non PHB producers remain white (FigNo.1). Most efficient PHB producer identified as Bacillus macquariensis as described by Bergey's Manual of Determinative Bacteriology. 


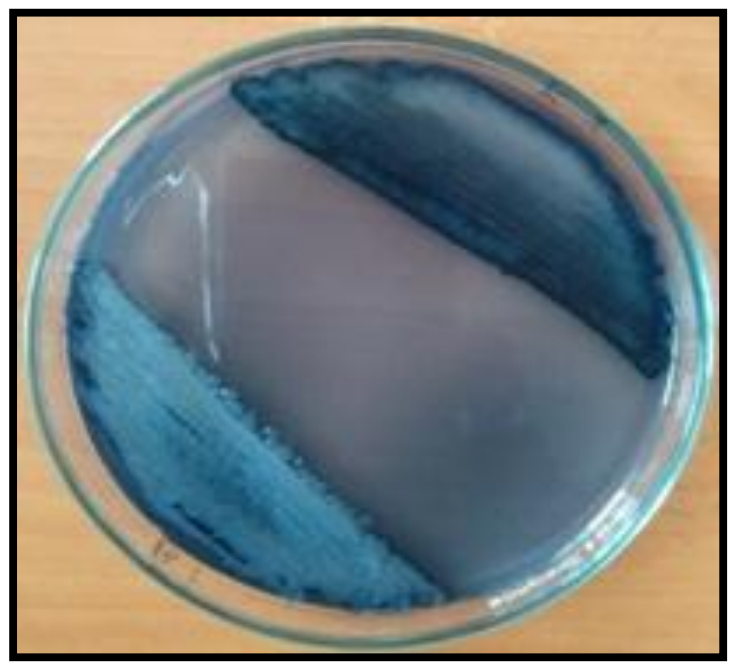

Figure 1.Sudan Black B(PHB producer screening)

\section{PHB Production and Extraction:}

By utilizing glucose as major carbon source, PHB production was maximum in modified LB medium as compare to nitrogen deficient medium after providing proper incubation condition (Fig No.2\&3). The selected bacterial isolates formed maximum $\mathrm{PHB}$ at $20 \mathrm{gm} / \mathrm{L}$ glucose in media. Sodium hypochlorite method was used for the extraction of PHB. After extraction, bacteria produced $2.10 \mathrm{~g} / \mathrm{L}$ of PHB (Figure 4). Extracted bacterial PHB was capable to produce bioplastic sheet.

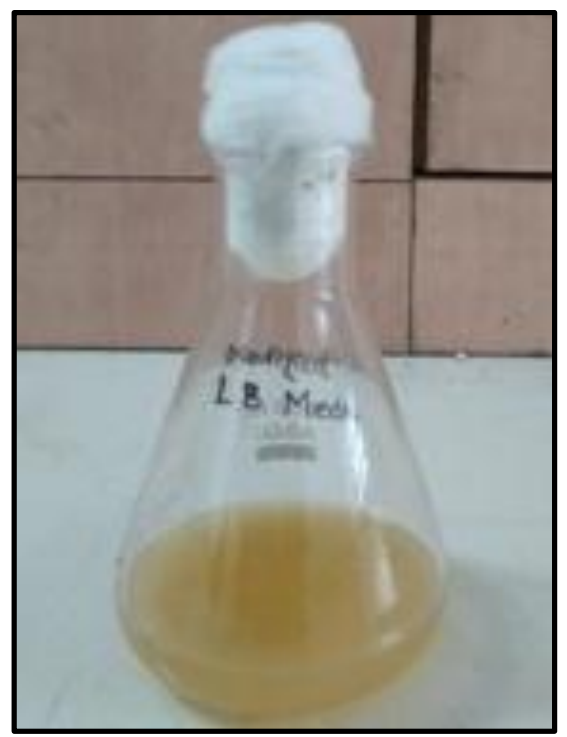

\section{Optimization parameters for PHB production:}

\section{Effect of Inoculums Percentage:}

Figure 2.Production in $\quad$ Modified LB medium

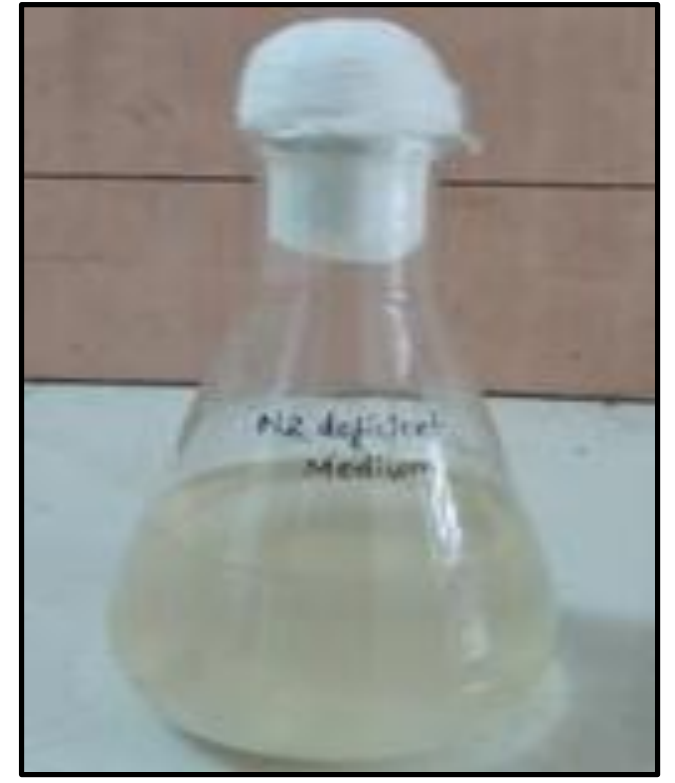

Figure 3 Production in Nitrogen Deficient Medium

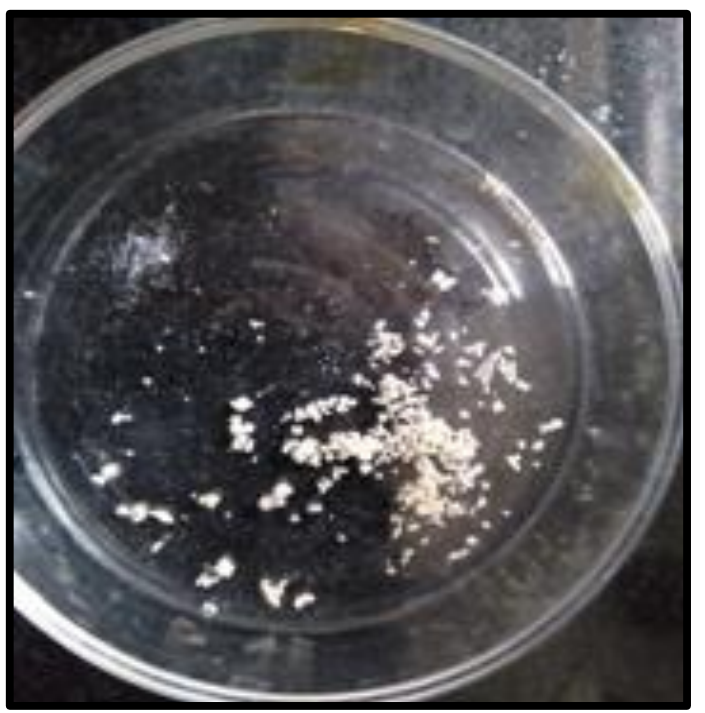

Figure 4.Extracted $P H B$ 
In the experiment, different inoculums percentage was analyzed for PHB production. The production of PHB found to be optimal at 3\% (Figure 5). The further increase in inoculums percentage decreases the production of PHB due to excessive growth of bacteria \& depletion of nutrients.

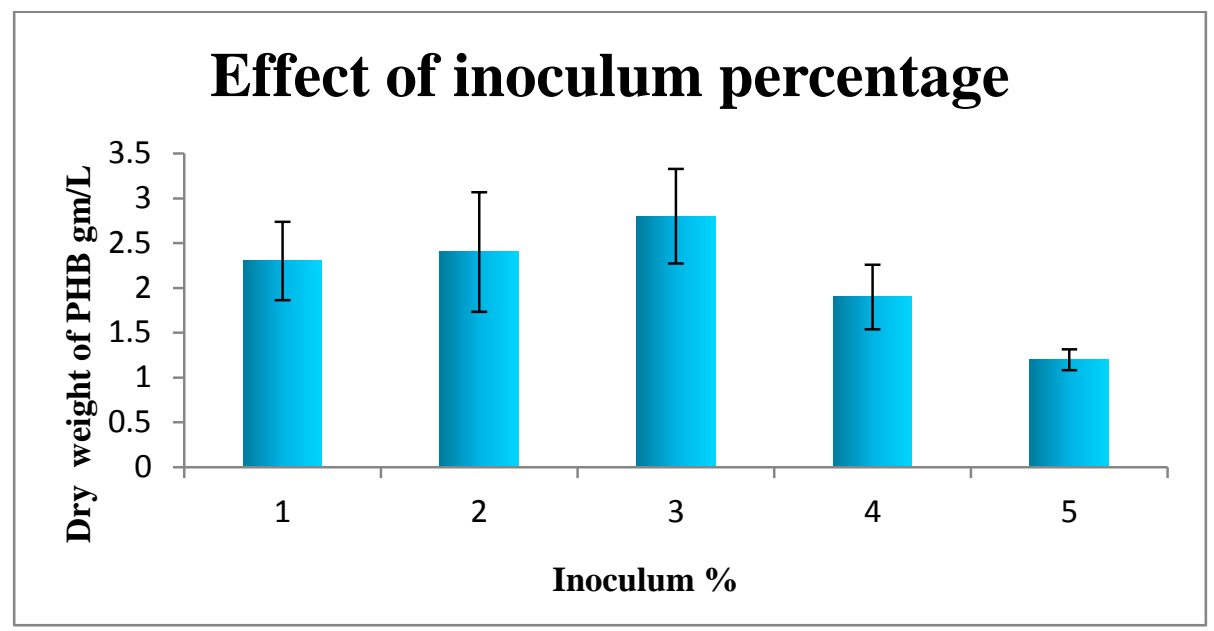

Figure 5.Effect of inoculums percentage on PHB production

\section{Effect of Glucose Concentration:}

Previously it reported that the maximum PHB production was occurs at higher glucose concentration. In present study, 20gm/L glucose concentration shows the maximum production of PHB by Bacillus macquariensis(Figure 6).

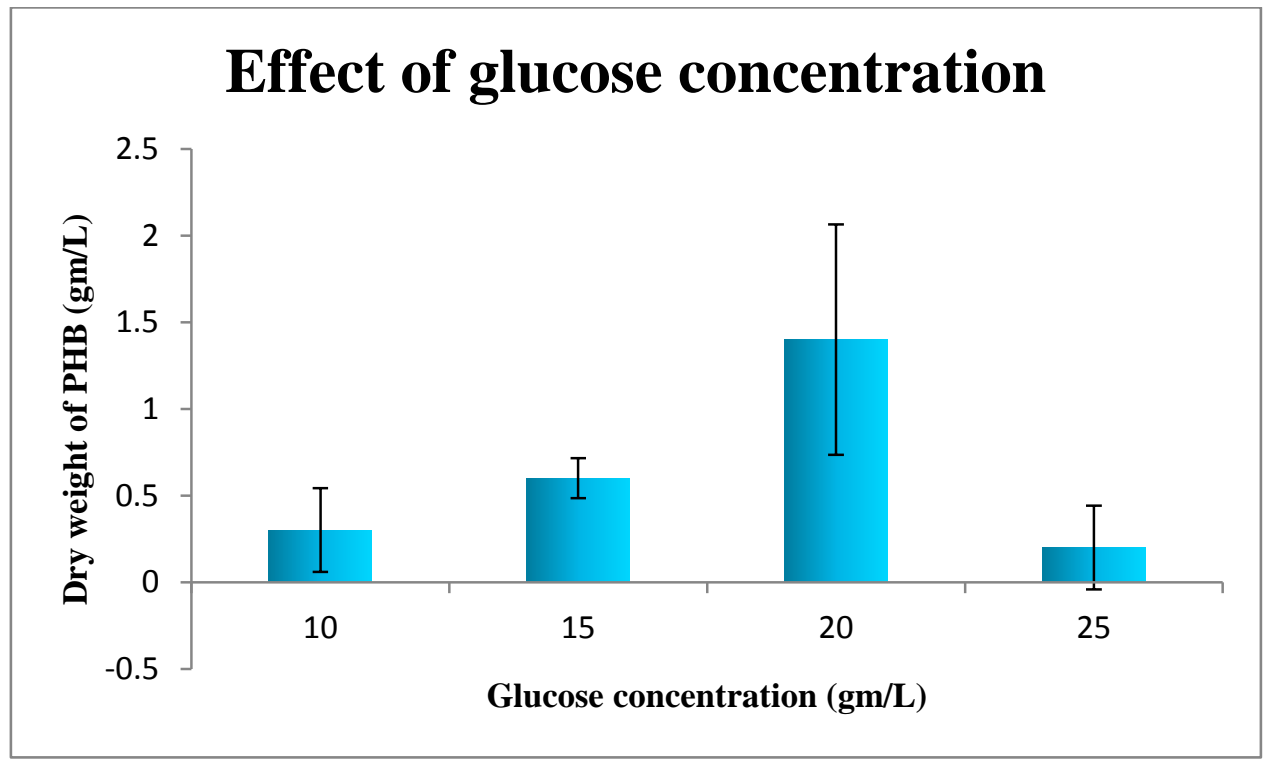

Figure 6.Effect of glucose concentration on PHB production

\section{Effect of Temperature:}

Different culture parameters like temperature, $\mathrm{pH} \&$ other culture parameters play an important role in PHB production. Hence, the optimum temperature for PHB production was found at $37^{\circ} \mathrm{C}$ for Bacillus macquariensis(Figure 7). 


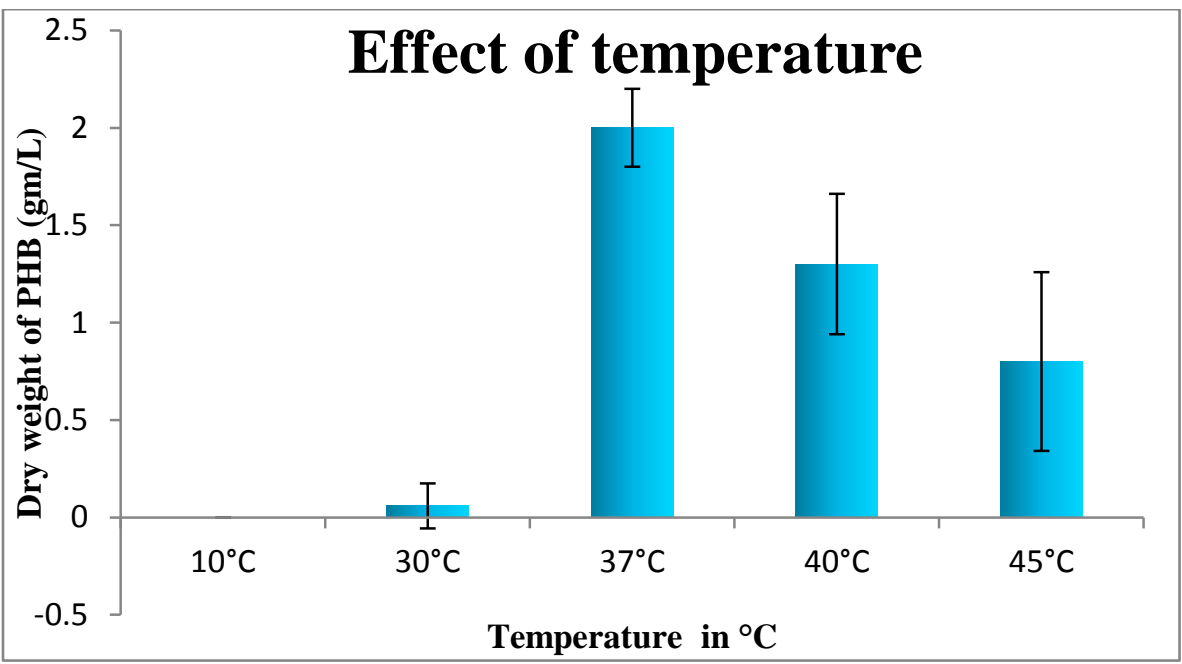

Figure 7.Effect of temperature on PHB production

\section{Effect of pH:}

Reaction \& transport of nutrients across the cell membrane of bacteria were affected by the $\mathrm{pH}$ of the media. Maximum PHB production takes place at suitable $\mathrm{pH}$. In present work the optimum $\mathrm{pH}$ for PHB production was observed at $\mathrm{pH} 7.5$ by Bacillus macquariensis (Figure 8).

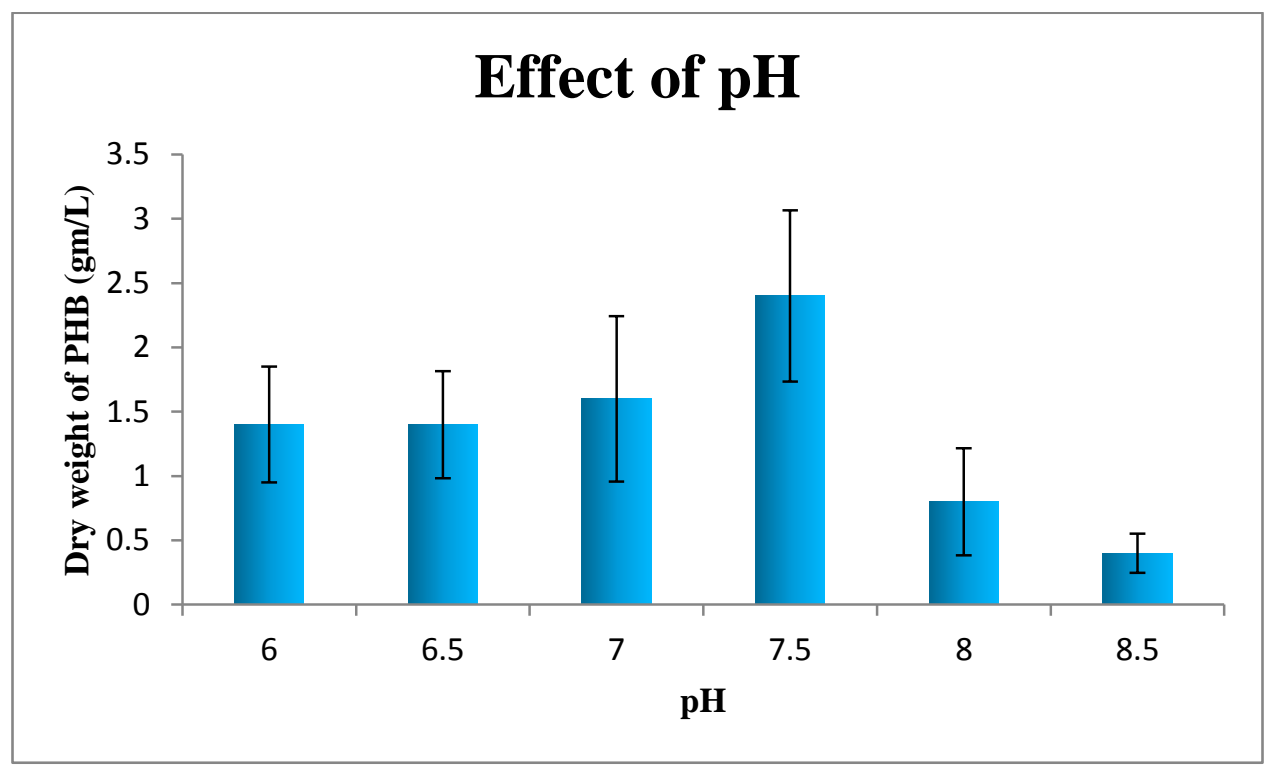

Fig.No.8 Effect of pH on PHB production

Statistical Analysis: Statistical Analysis was done by analysis of variance (ANOVA).

\section{Characterization of PHB:}

FTIR(Fourier Transform Infrared Spectroscopy): 
PHB characterization was done by Fourier Transform Infrared spectroscopy (FTIR). Band at $3326.56 \mathbf{c m}^{-1}, \mathbf{1 2 7 4 . 8 0} \mathbf{c m}^{-1}$, $1724.72 \mathrm{~cm}^{-1}$ and $2927.24 \mathrm{~cm}^{-1}$ represents O-H (hydroxyl), -COO (ester), C=O (carbonyl) and C-H (methyl) group respectively. These prominent absorption bands confirm that the extracted molecule was PHB.

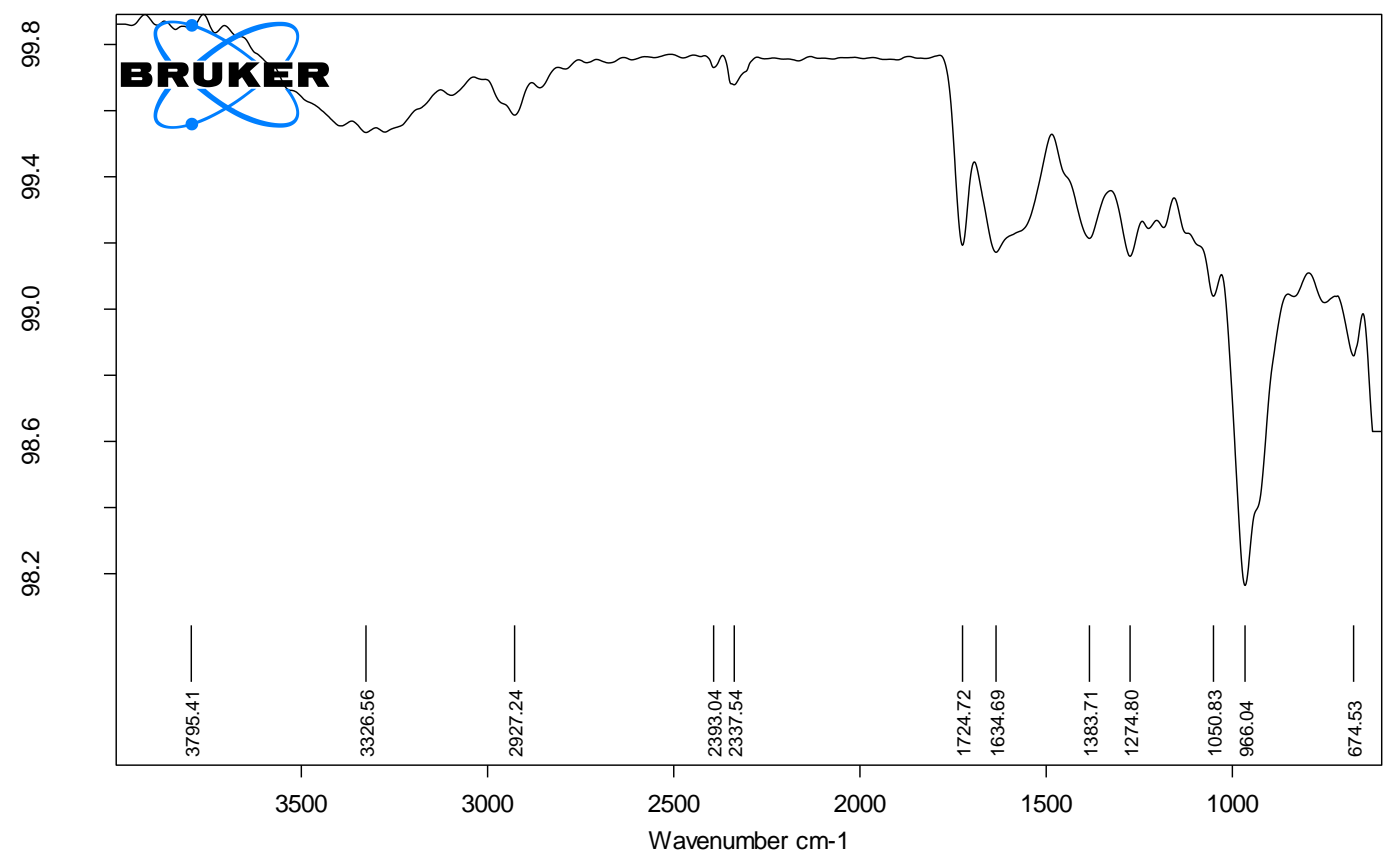

Figure 9.FTIR (Fourier Transform Infrared Spectroscopy)

\section{Thin Layer Chromatography:}

After evaluating PHB extract for TLC, brownish black color spot was appeared on TLC plate. The RF value calculated as $\mathbf{0 . 7 7}$ which was similar with the RF value of standard PHB. It confirmed the extracted PHB molecule.

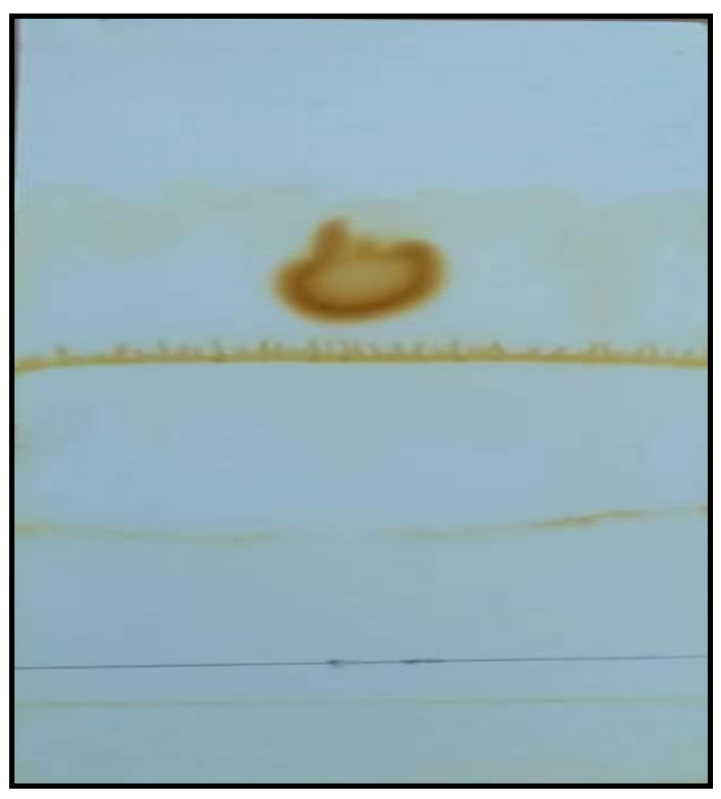

Figure 10.TLC of PHB 


\subsection{Preparation of bioplastic sheet from PHB:}

Formation of bioplastic sheet was not reported in previous literature. In present study, thin bioplastic sheet was made from extracted crude PHB, it showing the water tolerance activity, it repels the water.
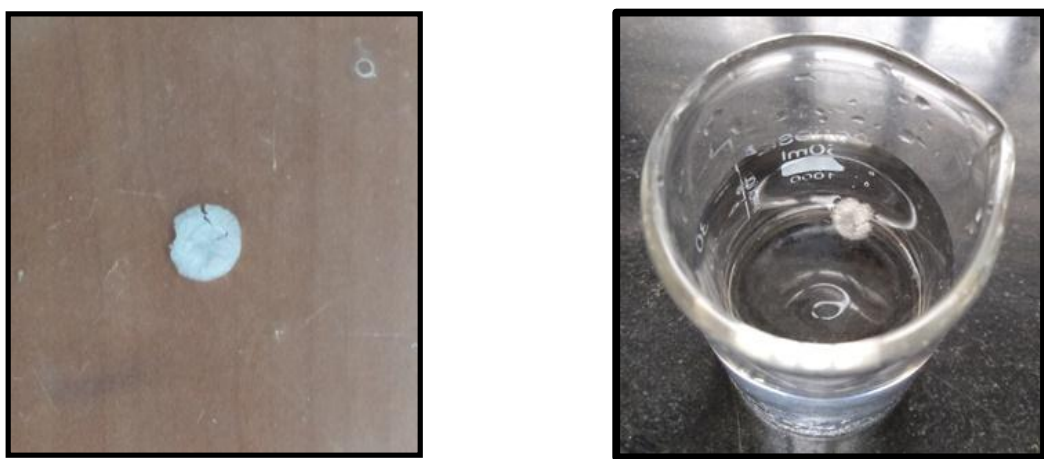

Figure 11.Bioplastic sheet and its water tolerance activity

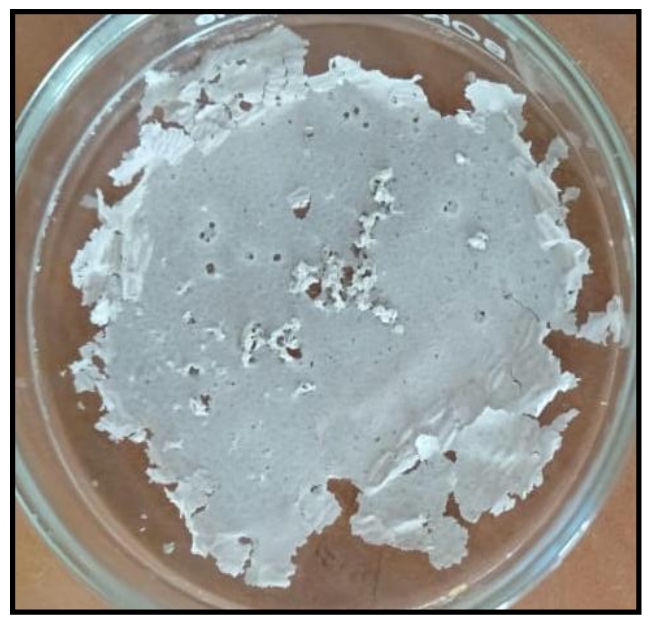

Figure 12.Bioplastic sheets after optimization

\section{DISCUSSION}

In the present study, 34 bacteria were isolated from collected samples \& screened for PHB producing capacity. The dark bluish black color forming isolate on Sudan black B staining was considered as best PHB producer. From 34 bacteria 25 bacteria showed the PHB accumulation. Hoseinabadi, (2015), in their research reported 61 bacteria from oil sludge sample and they got only 21 PHB producing bacteria. From 10 isolates, 6 PHB producers were obtained by Gupta Shraddha ${ }^{[7]}$, from cardboard industry waste water and rhizospheric soil respectively. We got more PHB isolates as compare to literature cited.The selected bacterial isolates after Sudan Black B staining produced maximum PHB when higher glucose $(20 \mathrm{gm} / \mathrm{L})$ was present in media. Bacillus subtilis gave highest PHB production in presence of $10 \mathrm{gm} / \mathrm{L}$ glucose concentration ${ }^{[15]}$. Senthil Kumar ${ }^{[8]}$ also got maximum PHB production in presence of glucose with $A$. eutrophus. In our work, PHB extraction was done by sodium hypochlorite method in which the bacterial isolates produced $2.10 \pm 0.5 \mathrm{~g} / \mathrm{L}$ PHB. $74 \mathrm{mg} / \mathrm{L}$ of PHB was produced by bacillus spp. isolated from organic waste and soil sample [15].

Most proficient PHB producer bacteria $\mathrm{B}_{1} \mathrm{III}$ in present work was identified by morphological and biochemical characterization. A bacterium was Gram positive, motile, rod shape. As per Bergey's Mannual of Determinative Bacteriology the most prominent PHB producer i.e. B1 III was identified as Bacillus macquariensis while Hawas ${ }^{[3]}$, identified their proficient bacteria as Pseudomonas boreopolis. Probabilistic identification of bacteria 
identification system was used by Gupta Shraddha ${ }^{[7]}$ for the identification of selected isolates i.e. Micrococcus luteus 2, Micrococcus mucilaginosus, Micrococcusnischinomiyaensis, Micrococcus radiodurans, Streptococcus equines, Streptococcusraffinolactis.

PHB characterization was done by Fourier Transform Infrared spectroscopy (FTIR) and thin layer chromatography (TLC) in present work. Band at $1271.09 \mathrm{~cm}^{-1}, 1724.72 \mathrm{~cm}^{-1}$ and 2927.94, $1379.10 \mathrm{~cm}^{-1}$ represents -COO (ester), C=O (carbonyl) and $\mathrm{C}-\mathrm{H}$ (methyl) group $\mathrm{COH}$ bond respectively. These prominent absorption bands correlate with the analysis of Alarfaj ${ }^{[2]}$ which confirming that the extracted molecule was PHB.Polymer extracted from Bacillus thuringiensis was subjected to FTIR, NMR, UVspectroscopy, DSC, TGA and LC-MS which confirm the presence of intracellular accumulated polymer. In FTIR hydroxyl, carbonyl, ester and methyl were corresponding to $3435,1731,1454$ respectively $^{[2]}$. In present study, after evaluating PHB extract for TLC, brownish black color spot was appeared on TLC plate. The RF value calculated as 0.77 which was similar with the RF value of standard PHB. It confirmed the extracted PHB molecule. The similar result was found by S. Sujatha ${ }^{[13]}$ in which they analyzed the PHB of different bacterial species.

Data presented by Hawas ${ }^{[3]}$ showed that, the maximum PHB production occurred at $30^{\circ} \mathrm{C}$ after 48 hours of incubation at a $\mathrm{pH} 7.0$ which was found to be optimum for PHB production by P.boreopolis J1. In our present work, we achieved maximum PHB production by Bacillus macquariensisat $37^{\circ} \mathrm{C}$ incubated for 48 hours at a $\mathrm{pH}$ 7.3. Different inoculums volumes and glucose concentrations were also tested for the production of PHB in which production was found to be optimal at $3 \%$ and $20 \mathrm{gm} / \mathrm{L}$ respectively. In previous literature cited cultural parameters like inoculums volumes and glucose concentration was not used for optimization purpose.Formation of bioplastic sheet was not reported purely from PHB in previous literature cited. In our project work, we made thin bioplastic sheet from extracted crude PHB, it showing the water tolerance activity.

\section{CONCLUSION}

25 bacteria showed PHB production. $2.10 \mathrm{~g} / \mathrm{L}$ PHB was extracted from selected bacterial isolates. Confirmation of PHB molecule was by FTIR \& TLC. The most prominent PHB producer identified as Bacillus macquariensis. PHB production was found to be maximum at optimum $\mathrm{pH} 7.5$, $37^{\circ} \mathrm{C}, 3 \%$ inoculums percentage and glucose concentration $20 \mathrm{~g} / \mathrm{L}$. Bioplastic sheet was successfully prepared from extracted bacterial PHB which was water tolerant.

\section{ACKNOWLEDGMENT}

I wish to express my deep sense of gratitude to my principal Dr. P.V. Ashtekar sir, principal, Shivchhatrapati College, Aurangabad, for giving permission to carry out the proposed work in the institute and sparing the facilities.

\section{REFERENCES}

[1]. Anish Kumari Bhuwal, ${ }^{1}$ Gulab Singh, Neeraj Kumar Aggarwal, Varsha Goyal\& Anita Yadav, " Isolation and Screening of Polyhyroxyalkanoates Producing Bacteria From Pulp, Paper, and Cardboard Industry Waste". Hindawi Publishing Corporation International Journal of Biomaterials, Vol. 2013, 752821, pp. 1-10, 2013.

[2]. Abdullah A. Alarfaj, Mohammed Arshad, Essam N. Sholkamy, Murugam A. Munusamy, "Extraction and Characterization of Polyhydroxybutyrate (PHB) from Bacillus thuringiensis KSADL127 Isolated from Mangrove Environments of Saudi Arabia." Brazilian Archives of Biology and Technology, Vol. 58, Issue., 5, 2015.

[3]. Jehan Mohammed El- Mohamedy Hawas, Tarek El-Said ElBanna, ElsayedBelalAbdelmontelebBelal, et.al., "Production of Bioplastic from some Selected Bacterial Strains." International Journal of Current Microbiology and Applied Sciences, Vol. 5, Issue., 1, pp. 10-22, 2016.

[4]. Akram Hoceinabadi ${ }^{1}$, Iraj Rasooli, MojtabaTaran, "Isolation and Identification of Poly $\beta$ - Hydroxybutyrate OverProducing Bacteria and Optimization of Producing Medium". Jundishapur J Microbiol, Vol. 8, Issue., 7: e16965, 2015.

[5]. Neelam K. Naranje, Bharat J. Wadher, Hemant J. Purohit, Manohar G. Muddeshwar, "Bacillus megaterium as potential producer for Polyhydroxybutyrate." IOSR Journal of Environmental Science, Toxicology and Food Technology, Vol. 1, Issue., 6, pp. 07-10, 2015.

[6]. S. Kumaravel, R. Hema \& R. Lakshmi, "Production of Polyhydroxybutyrate (bioplastic) and its Biodegradation by Pseudomonas lemoignei and Aspergillusniger." E Journal of Chemistry, Vol. 7, Issue.,S1, pp. S536-S542, 2010.

[7]. Gupta Shraddha, Rajput Yogita, Shit Simanta, ShuklaAparna, ShuklaKamlesh, "Screening and Production of bioplastic (PHAs) from Sugarcane Rhizospheric Bacteria." International Multidisciplinary Research Journal, Vol. 1, Issue., 9, pp. 30-33, 2011.

[8]. B. Senthil Kumar and G Prabhakarn, "Production of PHB (bioplastic) using bio-effluents substrate by Alcaligens eutrophus. " Indian Journal of Biotechnology, Vol. 5, pp. 7679, 2006.

[9]. Anteneh Getachew and Fantahun Woldesenbet "Production of biodegradable plastic by Polyhydroxybutyrate (PHB) accumulating bacteria using low cost agricultural waste material." Getachew and Woldesendet BMC Res Notes, Vol. 9, pp. 501-509, 2016.

[10]. Xiao-Ran Jiang, Huan Wang, Guo-Qiang Chen, "Engineering the bacterial shapes for enhanced inclusion bodies accumulation" Metabolic Engineering, Vol. 29, pp. 227-237, 2015.

[11]. Gulab Singh, Anish Kumari, Aparna Mittal, Anita Yadav \& Neeraj k. Aggarwal, "Poly $\beta$-Hydroxybutyrate Production by Bacillus subtilis NG 220 Using Sugar Industry Waste Water." Hindawi Publishing Corporation International Journal of Biomaterials, Vol. 2013, 952641, pp. 1-10, 2013.

[12]. Robert Findlay \& David C. White, "Polymeric BetaHydroxyalkanoates from Environmental Samples and 
Bacillus megaterium, Applied and Environmental Microbiology, Vol. 45, pp. 71-78, 1983.

[13]. S. Sujatha and D. Ravi, "A study on poly hydroxy butyrate (PHB) production and its application from Pseudomonas species (MTCC)." Biosciences, Biotechnology Research Asia, Vol.7, Issue., 2, pp. 825 -832, 2010.

[14]. Prayashree Bahalia, "Estimation of Kinetic Parameters for Production of PHB".

[15]. Wala'a Shawkat Ali, Neihaya Heikmat Zaki and Somaya Yassen Najim Obiad "Production of bioplastic by bacteria isolated from local soil and organic wastes." Current Research in Microbiology and Biotechnology Vol. 5, Issue., 2, pp. 1012-1017, 2017.

\section{Authors Profile}

Dr. Savita A. Kate pursed B.Sc., M.Sc. (Microbiology), DMLT, SET, Ph.D. in Microbiology from Sant Gadge Baba Amravati University, Amravati in1991, 1993, 1995, 2016 and 2018. She is currently working as a Head and Assistant Professor in Department of Biotechnology, SCCA, Aurangabad since 2007. She is life member of Microbiology

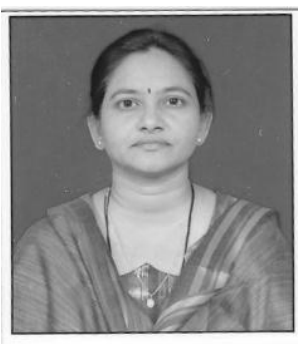

Society since 2010 . She has published more than 10 papers in reputed international journals and conferences. Her main research work focuses on Leather deterioration and preservation, Nanotechnology, Enzymology and Environment science. She has more than 15 yrs. teaching and 10yrs. Research experience. 